\title{
A SOCIEDADE COMO STAKEHOLDER DAS MINERADORAS
}

DOI: 10.37702/2175-957X.COBENGE.2021.3398

Hugo drumond chaves - hugo.chaves@aluno.ufop.edu.br

UFOP

RUA PORTO CARRERO 169

30441-185 - BELO HORIZONTE - MG

Luana Christina Francisco - luana.christina@aluno.ufop.edu.br

UFOP

Geraldo Baeta Barbosa, 1515

- Conselheiro Lafaiete - MG

Carlos Alberto Pereira - pereiraufop@gmail.com

UFOP

Rua João XXIII 240

35400-000 - Ouro Preto - MG

Resumo: $O$ propósito deste artigo é debater como a sociedade é importante para a mineração e como as mineradoras têm agido para reverter seus aspectos nocivos e gerar valor. Assim, mostrar que a mineração deixou de agir causando elevada degradação do meio ambiente e busca, cada vez mais, um desenvolvimento sustentável, tanto no quesito ambiental, quanto no social e econômico. Para que haja a melhoria é fundamental entender como funciona o processo licitatório, os problemas causados ao longo do tempo e o modo como são propostas as melhorias. Dentro desse contexto, o artigo põe em questão os diversos conflitos, projetos compensatórios e seus resultados, destacando a posição da sociedade como stakeholder. A partir disso, é possível compreender a atuação das mineradoras e sua importância para que as comunidades se desenvolvam e consigam atingir os Objetivos de Desenvolvimento Sustentável da ONU.

Palavras-chave: Mineração sustentável. Licença social. ODS. 


\section{INTRODUÇÃO}

A mineração uma das atividades da economia brasileira, constituindo cerca de $4 \%$ do Produto Interno Bruto (PIB), segundo o Instituto Brasileiro de Mineração - IBRAM (2021). A razão desse valor é a quantidade expressiva de empreendimentos minerários no país, que são responsáveis também pela geração de milhares de empregos diretos e milhões de indiretos. Por outro lado, a mineração também apresenta consequências negativas ao meio ambiente e social, causando polarização de opiniões e consequências irreversíveis para o ecossistema.

$\mathrm{O}$ presente trabalho busca debater a forma como a sociedade é envolvida no setor da mineração, explicitando sua importância na tomada de decisões e as consequências que podem ou foram geradas em alguns casos. Por essa razão, foi escolhido o termo stakeholder, que significa parte interessada que é impactada e pode impactar as decisões de uma determinada empresa.

A metodologia adotada para o desenvolvimento deste estudo foi baseada em uma pesquisa de enfoque qualitativo com procedimentos típicos de uma revisão bibliográfica. Para tanto, foram consultados relatórios das mineradoras, a regulamentação gerida pela Agência Nacional de Mineração (ANM), os Objetivos de Desenvolvimento Sustentável (ODS) da Organização das Nações Unidas (ONU), artigos e reportagens sobre o tema. Essa pesquisa possibilitou discorrer sobre três aspectos principais: o processo licitatório, abordando as licenças e trâmites; as influências negativas das mineradoras, com seus impedimentos e efeitos, e as influências positivas, com seus resultados e ganhos com base nas ODS.

\section{PROCESSO LICITATÓRIO}

A regulamentação do processo licitatório se iniciou na década de 30, a partir da Constituição Brasileira promulgada no Governo de Getúlio Vargas, com a separação da forma de tratamento das jazidas minerais presentes no solo e subsolo. Sua efetivação se deu com a criação do Departamento Nacional de Produção Mineral - DNPM, atual ANM, órgão cuja função principal é a fiscalização das leis que regulamentam as jazidas, e com a publicação do Código de Minas, posteriormente substituído pelo Código de Mineração, em 1967.

O novo modelo trouxe mudanças e avanços para o setor minerário na época, como a regulamentação de massas de substâncias minerais, encontradas tanto na superfície quanto no interior da terra, e seus regimes de aproveitamento. Consolidado perante ao cenário mineral nacional, o mesmo é utilizado até os dias atuais (BRASIL, 2013).

\subsection{Processo Minerário}

Baseado no Código de Mineração e na Constituição Federal, e regulamento pela ANM, o processo minerário trata-se de um processo administrativo solicitado perante a ANM, onde a pessoa ou empresa solicitante possui direito e prioridade para comercializar as substâncias minerais persentes dentro da área solicitada.

O processo é dividido em uma série de ações que variam de acordo com o tipo de Regime de Aproveitamento de Pesquisa Mineral. Essas especificações foram criadas com o intuito de dividir os processos minerários de acordo com o tipo de substância mineral, o grau de complexidade de seu aproveitamento e o destino da produção, divididos em quatro tipo de regimes: Regime de concessão e autorização, Regime de permissão de lavra garimpeira, Regime de monopolização, e o Regime de Extração. Dessa forma, é aplicada a cada um dos regimes uma série de etapas para o processo licitatório, bem como variam, de acordo com o regime, os tipos de documentos e licenças necessários para a aprovação do requerimento minerário. 


\subsection{Licenças Ambientais}

Aliado ao processo de requerimento minerário, junto à ANM, há a o licenciamento ambiental, que por sua vez ocorre junto aos órgãos ambientais de cada estado da Federação. O mesmo pode ser identificado como processo administrativo, onde o respectivo órgão ambiental regulamenta a licença, localização, instalação, ampliação e a operação de empreendimentos e atividades que utilizam de recursos minerais passiveis de causar algum tipo de degradação ambiental (CONAMA, 1997).

Perante a legislação, existem três licenças ambientais que são necessárias para regulamentar um empreendimento mineiro. A licença prévia (LP), solicitada na fase preliminar do empreendimento, de forma a atestar a viabilidade ambiental do mesmo e definir os requisitos necessários para as etapas posteriores. A licença de instalação (LI), que autoriza a instalação de acordo com o projeto. E, por fim, a licença de operação (LO), que após o cumprimento das requisições anteriores, autoriza o início das operações.

A não conformidade com as exigências e requisitos ambientais impacta ou na não liberação de uma ou mais licença ou até na revogação das mesmas. Situação semelhante à enfrentada pela AVG Mineração, na Mina do Brumado, localizada na Serra da Piedade. Nessa situação, a licença de operação da empresa foi suspensa devido a irregularidades no plano de extração mineral, extrapolando os limites previstos, e às técnicas de disposição de rejeitos, que não cumprem aspectos de segurança geotécnica e ambiental. (DOM TOTAL, 2021)

\subsection{Licença Social}

Atualmente, vem sendo difundido o conceito da Licença Social para operar (LSO), aplicado à indústria mineral como ferramenta de gestão com o intuito de aumentar a aceitabilidade das operações e contribuir para a mitigação de riscos das atividades minerárias (JOYCE E THOMPSON, 2000). Essa licença é baseada no pressuposto da constante aprovação da sociedade sobre um empreendimento minerário, onde a mesma, ao longo do desenvolvimento das atividades da empresa pode dar ou recusar apoio às suas operações. De acordo com Gunningham, Kagen, Thorton(2004 apud SANTIAGO) o nível do apoio varia de acordo com as expectativas da sociedade, sendo correlacionado com a maneira que a empresa conduz suas operações e conforme as expectativas são atendidas. A ausência desse apoio é apontada como o maior e principal risco do setor minerário, pela pesquisa da consultoria Ernst \& Young 2019/2020, de forma que a LSO aumenta o valor compartilhado dos projetos. Por conseguinte, as empresas do setor minerário buscam modelos de negócios que sejam competitivos e acrescente positivamente os stakeholders.

Um exemplo dessa preocupação pode ser observado no Projeto Juriti, pertencente à empresa Alcoa, localizado no município de Juruti - Pará, onde a empresa opera uma mina para extração de bauxita. Para esse projeto em questão, a empresa realizou uma série de ações visando reduzir impactos socioambientais e promover o desenvolvimento local, e por consequência conquistar a LSO. Nesse caso, essas ações ocorrem em parceria com o poder público e a sociedade civil local, por meio de uma proposta de desenvolvimento intitulada "Juriti Sustentável". Essa proposta é baseada em dois eixos principais: Fundo Juruti Sustentável, que visa fornecer apoio ao desenvolvimento local, por meio de projetos sociais e ambientais; e o Conselho Juruti Sustentável (CONJUS), um fórum institucional com o objetivo de criar um espaço de participação ampla e democrática das partes interessadas, e dessa forma estimular o diálogo entre as partes, no processo de definição das políticas de desenvolvimento local (ABDALA, 2015).

\section{INFLUÊNCIAS NEGATIVAS DAS MINERADORAS}

As mineradoras são frequentemente rejeitadas, principalmente quando se trata da implementação de novos empreendimentos mineiros. Essa carga de responsabilidade está ligada aos impactos que a atividade gera em uma região, alterando completamente o status quo. Com o início 
da pesquisa e exploração, são alteradas as paisagens, assim como os recursos hídricos e ambientais, a comunidade e a economia da região, desagradando a população local. Recentemente, a mineradora Herculano foi alvo de protestos na região do Serro - MG, com um projeto ambicioso e com suspeita de irregularidades. Segundo reportagem do Estado de Minas (2021), movimentos populares da região se organizaram em uma luta contra as atividades da mineradora.

Com base em publicações, artigos e reportagens, serão discutidas a seguir as principais influências negativas geradas pela atividade de extração mineral, visando entender o problema e estudar casos específicos.

\subsection{Mão de obra}

Ao iniciar um projeto de mineração, a comunidade local direciona suas energias para sua construção e implementação. Algumas características desse fluxo são surgimento de empresas e desenvolvimento de outras já presentes, criando empregos principalmente nas áreas de consultoria e serviços. Por outro lado, empregos em outras áreas vão se deteriorando e os setores perdem poder ao concorrer com as mineradoras. São exemplos os casos da Vale em Itabira - MG, que acabou extinguindo o setor têxtil da economia local, e a Quinos em Paracatu - MG, que se envolveu em um conflito local com os agricultores pelo alto consumo da água (FERNANDES \& ENRÍQUEZ, 2011).

Além disso, a mineração é um setor extremamente específico e devido às suas características exige uma mão de obra qualificada. Como consequência dessa exigência, os empregos diretos gerados pela mineração na região são baixos, criando uma importação de trabalhadores, que por sua vez introduz uma alta concentração de renda, resultando em um aumento da desigualdade social da região. De acordo com o Relatório de Impacto Ambiental (RIMA) da mineração Belo Sun (2012), no meio socioeconômico, a oferta de mão de obra excedente e a contratação de trabalhadores provenientes de outros municípios causam um aumento nos portes demográficos dos municípios, pressionando dessa forma os equipamentos e serviços de segurança pública, educação, saúde e infraestrutura urbana.

Somada ao desequilíbrio social, a implementação de mineradoras em algumas regiões gera também um desequilíbrio entre os gêneros. Isso ocorre devido à contratação, em sua maioria, de mão de obra masculina, enquanto as mulheres acabam migrando em busca de outros postos de trabalho. Como efeito dessa situação, é comum o aumento tanto da prostituição, com mulheres buscando saídas à falta de emprego, como também do índice de gravidez na adolescência (VILHENA, 2019).

\subsection{Deslocamento compulsório}

A remoção de famílias que ocupam áreas de grande interesse e alto potencial mineral é uma causa comum para conflitos sociais com mineradoras. Durante a confecção do projeto de implementação de uma mineração são realizados estudos de áreas e riscos. Em determinados casos, é fundamental o reassentamento social para a extração segura dos bens minerais.

As famílias que são removidas compulsoriamente recebem uma indenização por suas terras e, na maior parte dos casos, a realocação é feita visando o mínimo deslocamento da família. A razão é diminuir ao máximo a descaracterização social, a perda de identidade e valores da população (SEPE \& SALVADOR, 2018). Infelizmente, não são todos os casos que possibilitam uma mudança próxima à área inicial e, de acordo Vilhena (2019), os resultados são: desemprego, pois devido à realocação o antigo emprego passa a ser distante ou afeta a família que dependia da agropecuária; migração urbana, onde os afetados buscam outras formas de emprego em centros urbanos, aumentando a taxa de êxodo; alteração na balança de alimentos, ocasionada pelo aumento populacional repentino e alteração da fonte de renda de núcleos familiares (que antes supriam a região com a agropecuária), aumentando a demanda e diminuindo a produção.

Um exemplo do confronto população-mineradora é citado em "Deslocamento compulsório e estratégias empresariais em áreas de mineração” (2009). Nessa situação, a ALCOA retirou 10 famílias 
e ocupou lotes de um assentamento em Juruti-PA, resultando em conflitos com a população local motivados pelos baixos valores disponibilizados, aquém do previsto pelos lesados.

\section{3 Água}

Como apresentado na Agenda 21, Conferência da ONU sobre Meio Ambiente e Desenvolvimento (1992), a água é identificada como recurso necessário em todos os aspectos da vida. Portanto, deve ser ofertada, a toda a população mundial, mesmo que seja necessário a adaptação das atividades aos limites da natureza e o desenvolvimento de tecnologias para aproveitamento integral dos recursos hídricos. Na mineração, a água é considerada um recurso estratégico, por ser essencial para processos e operações, sendo aplicada desde a exploração da jazida até o beneficiamento do minério.

Segundo a consultoria Ernest \& Young (2015), o acesso à água é apontado como um dos riscos do setor minerário, pela mesma ser identificada como um recurso finito. Logo, a gestão consciente visando as melhores alternativas para a sua acessibilidade e qualidade tornaram-se fatores diferenciadores do sucesso operacional no setor minerário. E de maneira oposta, pode acarretar em sérios problemas para a empresa envolvida e para a comunidade ao redor.

Como exemplo, o estudo de caso realizado por Pereira et al (2016) sobre as populações da região composta pelos municípios de Conceição do Mato Dentro, Alvorada de Minas e Dom Joaquim - MG, que foram afetadas pelo Projeto Minas-Rio, da empresa Anglo American, exemplifica como a má gestão dos recursos hídricos pode acarretar em mudanças significativas no cotidiano das comunidades. Isso porque as comunidades afetadas dependiam da agricultura familiar para a geração de renda, e após o projeto se viram privados da utilização dos recursos naturais da região. Como medida de compensação, a empresa fornece uma caixa d'água, que é abastecida por caminhões pipa, para a captação de água para as comunidades fragilizadas (SEPE; SALVADOR, 2018).

\section{INFLUÊNCIAS POSITIVAS DAS MINERADORAS}

A partir dos pontos apresentados, fica claro que a implementação de um projeto minerário atinge de maneira direta o estilo de vida da sociedade local. A mineração é um setor que, por muito tempo foi a raiz de diversos problemas para as comunidades locais, a degradação ambiental, deslocamento de populações, conflitos armados, evasão fiscal e corrupção (PNUD et al., 2017). Atualmente, por pressões da sociedade, adoção de novas legislações pelo Estado e visando um desenvolvimento mais sustentável, as mineradoras estão realizando diversos projetos voltados para a região onde atuam, trazendo infraestrutura, melhoria nas condições de vida, gerando emprego e pensando no meio ambiente.

As mineradoras Vale, CBA, Alcoa, Nexa e Anglo American já alinham seus projetos de compensação e desenvolvimento com base nos ODS da ONU. Os ODS são formados por 17 tópicos, separados em 3 diferentes âmbitos, o social, ambiental e econômico (Figura 1). Juntos, eles representam uma agenda mundial que busca o crescimento, a equiparação e a conscientização em busca de uma produção mais "bio amigável".

Imagem 1: ODS por eixo de atuação 


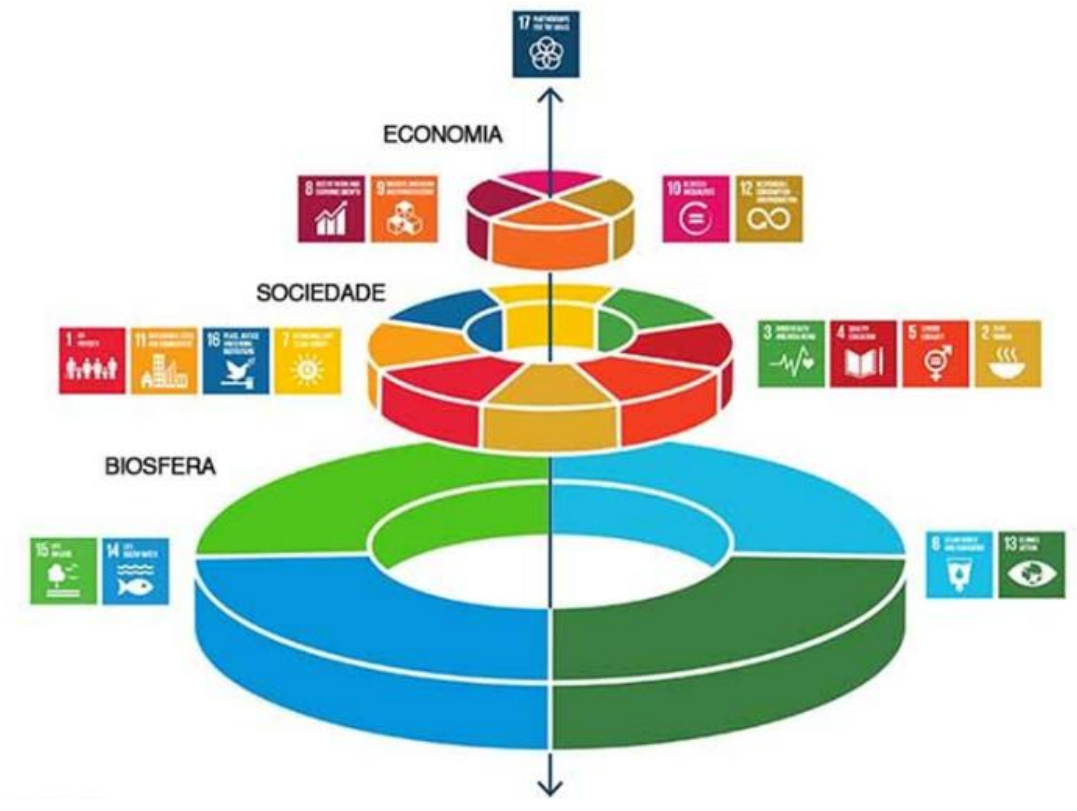

Fonte: Agenda 2030 (2015).

\subsection{Desenvolvimento econômico}

Entre os três pilares, encontra-se o econômico, que engloba quatro ODS que buscam a melhoria financeira da população com a garantia de empregos decentes, evolução na tecnologia e infraestrutura, redução da desigualdade social, ao mesmo tempo que visa fortalecer o consumo e produção sustentáveis.

O ODS 8 promove o crescimento econômico sustentado, inclusivo e sustentável, emprego pleno e produtivo e trabalho decente para todos e todas. Em outras palavras, esse objetivo busca garantir oportunidades e empregos para as populações mais vulneráveis de forma a aumentar a expectativa de vida, permitir a qualificação das pessoas e melhorar as perspectivas de emprego (AGENDA 30, 2015).

Um exemplo da aplicação deste ODS no setor da mineração, atualmente, é o projeto Promova, da Anglo American. Segundo o Relatório à Sociedade - Negócio Níquel (2019), o programa visa ajudar fornecedores de Niquelândia - GO, a se desenvolverem de maneira sustentável. A iniciativa promove treinamentos técnicos e medidas de estímulo a parcerias, gerando investimentos de 317 milhões em compras locais. Como consequência dessa união, os fornecedores locais saem qualificados, o comércio local mais fortalecido e a cidade mais sustentável economicamente.

O ODS 10 busca combater as desigualdades dentro dos países. De acordo com a Agenda 30 (2015), alcançamos o maior nível de desigualdade mundial desde 1940. Por esse motivo, o objetivo visa erradicar a pobreza, reduzir a desigualdade socioeconômica e combater as discriminações.

Atualmente, as mineradoras trabalham essa ODS de maneira ativa, apoiando projetos sociais, buscando incluir minorias em seus processos seletivos e apoiando iniciativas locais. A Vale serve de modelo para esse objetivo, com o projeto Rede Mulheres do Maranhão (RMM). A iniciativa qualificou e incentivou um grupo formado por mais de 100 mulheres. Dessa forma, os diferentes negócios que incluem fabricação de doces, confecção de roupas, beneficiamento de babaçu e castanha de caju, panificação e cultivo de verduras e legumes, impactaram no desenvolvimento local e contribuíram para a qualidade de vida das mulheres e suas famílias (VALE, 2019). 


\subsection{Desenvolvimento social}

O viés de desenvolvimento social conta com oito objetivos sustentáveis de desenvolvimento, e visa a erradicação da fome e da pobreza, igualdade de gênero, educação de qualidade, comunidade sustentável, energia limpa e acessível, buscando paz, justiça e instituições eficazes (ONU, 2018).

O ODS 4, Educação de Qualidade, busca a educação inclusiva e de qualidade, de forma a promover oportunidade de aprendizagem para todos ao longo da vida. Com base no ensino, esse objetivo visa ampliar as oportunidades das pessoas mais vulneráveis, em busca do desenvolvimento.

Baseada na premissa que os colaboradores são capazes de promover as melhorias que a empresa necessita, é necessário ter pessoas capacitadas, motivadas e com espaço para o desenvolvimento. A CBMM possui programas que buscam aperfeiçoar talentos, incentivar desafios e expandir as oportunidades de seus colaboradores, como o Projeto Jovem Aprendiz, em parceria com o Senai, que desenvolve competências ligadas a vagas de operação, e o Projeto Educação Para Todos, que oferece auxílio-educação para a incentivar os colaboradores a estudar (cursos técnicos e superiores) (CBMM, 2019).

O ODS 11, Cidade e comunidades sustentáveis, que remete a temas como mobilidade, gestão de resíduos e saneamento, tem como objetivo direto tornar as cidades e comunidades mais inclusivas, seguras, resilientes e sustentáveis.

A AngloGold é referência desse ODS com o Programa Parcerias Sustentáveis, que visa transformar as comunidades em que possuem operação, tendo como principal ação para tal, o incentivo aos empreendedores locais, de forma a contribuir com o desenvolvimento social, cultural e econômico das cidades. O projeto busca iniciativas que compactuam com pelo menos um ODS e que possuam maior potencial de transformação social. Para o ano de 2019, 23 iniciativas foram escolhidas, totalizando aproximadamente $\mathrm{R} \$ 1.057 .050$ milhões de reais investidos e cerca de 2.521 pessoas impactadas direta e indiretamente (ANGLOGOLD, 2019).

\subsection{Proteção ambiental}

Para o eixo ambiental, a ONU propõe preservação e conservação do meio ambiente, possuindo ações que visam o uso sustentável dos recursos hídricos, a proteção das florestas e da biodiversidade, reversão ao desmatamento e adoção de medidas efetivas contra mudanças climáticas. Dentre elas, podem ser citadas os ODS's 13 e 15.

O ODS 13, Ação Contra a mudança global do clima, busca adotar medidas necessárias para combater as alterações climáticas e seus possíveis impactos. Em outras palavras, busca adotar medidas climáticas com o intuito de reduzir o impacto gerado, por meio da conscientização, educação e ações mitigadoras.

A Alcoa, com base nesse objetivo, trabalha com o sistema de compensação de emissões. Em Juruti (PA), o Projeto Locomotiva Verde é um exemplo de compensação de emissões de dióxido de carbono resultantes do transporte ferroviário, através da recuperação de áreas nas comunidades locais. Com quatro comunidades envolvidas, são contabilizados cerca de 40 hectares restaurados, totalizando 68 mil mudas plantadas, neutralizando 11 mil toneladas de CO2 (ALCOA, 2019).

Já o ODS 15, Vida Terrestre, visa proteger, restaurar e promover o uso sustentável dos ecossistemas terrestres, gerir de forma sustentável as florestas, combater a desertificação, reverter a degradação dos solos e parar a perda da biodiversidade (ONU, 2018).

A Companhia Brasileira de Alumínio - CBA, em parceria com a Nexa, Votorantim Cimentos e Votorantim Energia, contam com o Legado da Águas, maior reserva privada de Mata Atlântica do Brasil, com 31 mil hectares localizada no interior de São Paulo, fundado em 2012. Com o objetivo de oferecer um legado positivo à sociedade, aliando a proteção das florestas e o desenvolvimento de pesquisas científicas a atividades da nova economia, como o ecoturismo, para contribuir para o desenvolvimento social e econômico da região (CBA, 2019 e RESERVAS VOTORANTIM, 2019). 


\section{CONSIDERAÇÕES FINAIS}

Atualmente, as opiniões sobre a mineração, em sua maioria, divergem entre si. Por um lado, muitos reconhecem a mineração como indústria essencial para a economia brasileira, devido à porcentagem expressiva no PIB, na movimentação da economia e na geração de milhares de empregos. Em contrapartida, é crescente a conscientização das consequências negativas das mineradoras ao meio em que se encontram inseridas, influenciando negativamente um de seus stakeholders, a sociedade. Sendo o aspecto social o mais abordado, com o deslocamento de famílias locais e importação de mão de obra, aumentando a desigualdade social das regiões, ou o ambiental, com a alteração das paisagens e da distribuição dos recursos hídricos, com a implantação de empreendimentos mineiros.

Entretanto, com a análise apresentada neste trabalho conclui-se que as atividades da mineração brasileira se inter-relacionam com os ODS. Sendo, portanto, uma possibilidade para os empreendimentos minerários, reverterem a visão social negativa a eles atrelados, e oferecer a comunidade, principal stakeholder da atividade minerária, projetos e ações com impactos positivos aos mesmos. Contudo para tal, a fiscalização dessas atividades tem um papel significativo, uma vez tanto os governos quanto a ONU buscam avançar na agenda dos ODS para os setores de petróleo, gás e mineração.

Dessa forma, as empresas que possuem a preocupação com o meio ambiente e buscam a sustentabilidade como um de seus pilares visam alinhar o desenvolvimento sustentável à atividade de extração. É uma necessidade urgente tornar a mineração uma atividade menos invasiva ao meio ambiente, utilizando a tecnologia para mitigar e compensar os impactos gerados e trazendo investimentos para ações educacionais e sociais. Por consequência, os ODS da ONU são hoje os principais meios de se alcançar o desenvolvimento sustentável para a mineração no Brasil e no resto do mundo.

\section{REFERÊNCIAS}

ABDALA, F. Mineração e Sustentabilidade: o Caso da Mina de Bauxita de Juruti. Trabalho apresentado no evento Iniciativas Inovadoras em Monitoramento do desenvolvimento Local e Avaliação de Impacto (IDLocal), Fundação Getúlio Vargas, 04 de agosto de 2015, São Paulo-SP.

BRANDT. Meio ambiente: Belo Sun mineração. (2012). Projeto Volta Grande do Xingu: nota técnica de esclarecimento das principais questões abordadas na audiência pública do senador José Porfírio. Senador José Porfírio.

AGÊNCIA NACIONAL DAS ÁGUAS - ANA; A gestão dos recursos hídricos e a mineração. Instituto Brasileiro de Mineração - IBRAM. (2006). Brasília: ANA, 334 p.

ALCOA. Relatório de Sustentabilidade - Brasil. 2019. Disponível em: https://www.alcoa.com/brasil/pt/sustainability Acesso em 26 jan 2021.

ANGLO AMERICAN. Relatório à Sociedade 2015-2016-2017. 2019. Disponível em: https://www.angloamerican.com.br. Acesso em 27 jan 2021.

ANGLO GOLD. Relatório de Desenvolvimento Sustentável .2019. Disponível em: https://www.anglogoldashanti.com.br/. Acesso em 06 fev 2021.

BRASIL, Ministério de Minas e Energia. Histórico da Mineração Brasileira, 2013. Disponível em: http://antigo.mme.gov.br/documents/36108/439734/Linha_do_tempo.pdf/ Acesso em: 21 mar. 2021. 
BRASIL. (19 de dezembro de 1997). Licenciamento Ambiental, Resolução Conama, № 287. Diário Oficial da União.

CBA. Relatório Anual.2019. Disponível em: https://www.cba.com.br/RelatorioAnual2019/ Acesso em 26 jan 2021.

CBMM. Relatório de Sustentabilidade 2019.2019. Disponível em: https://cbmm.com/assets/sustainability-report-2019/pt/Acesso em 30 jan 2021.

CONFERÊNCIA DAS NAÇÕES UNIDAS SOBRE MEIO AMBIENTE E DESENVOLVIMENTO. Agenda 21. Brasília: Senado Federal, Subsecretaria de Edições Técnicas, 1996. 585 p.

DOM TOTAL. Licença ambiental de mineração na Serra da Piedade é suspensa pelo TJMG 24 fev. 2021. Disponível em: https://domtotal.com/noticia/1501328/2021/Acesso em: 21 mar. 2021.

FERNANDES, F. R. C. Enriquez, M. A. R. S. ALAMINO, R. C. J. Recursos minerais \& sustentabilidade territorial: grandes minas. Rio de Janeiro: CETEM/MCTI, 2011. V.1.

IBRAM. Artigo - Licença social para operar: transformando riscos em valor. 30 jul. 2017. Disponível em: https://ibram.org.br/noticia/artigo-licenca-social-para-operar-transformando-riscosem-valor/ Acesso em: 21 mar. 2021.

IBRAM. Mineração em alta. 24 mar. 2021. Disponível em: https://ibram.org.br/noticia/mineracaoem-alta-2/ Acesso em: 21 mar. 2021.

JOYCE, S., \& THOMSON, I. Earning a social licence to operate: social acceptability and resource development in Latin America. Cim Bulletin, 2000. 93(1037), 49-53.

MARTINS, Humberto. Movimentos populares do Serro criticam prefeito e tentam impedir mineração. Estado de Minas, Belo Horizonte. 2 fev. 2021. Disponível em: https://www.em.com.br/app/noticia/gerais/2021/02/08/interna_gerais, 1236033/movimentospopulares-do-serro-criticam-prefeito-e-tentam-impedir-mineracao.shtml. Acesso em: 25 mar. 2021.

ONU. Organização das Nações Unidas. Objetivos de Desenvolvimento Sustentável. 2018. Disponível em https://brasil.un.org/pt-br/sdgs Acesso em 26 jan 2021.

ONU. Organização das Nações Unidas. Transformando Nosso Mundo: A Agenda 2030 para o Desenvolvimento Sustentável. 2015. Disponível em: http://www.agenda2030.com.br/ Acesso em 26 jan 2021.

PEREIRA, V. G.; BELLEZE, G.; BATTISTON K. de M.; PEREIRA, S. B.; PIMENTA, C. A. M. O potencial da agricultura familiar das comunidades rurais atingidas pela mineração nos municípios de Alvorada de Minas, Conceição do Mato Dentro e Dom Joaquim: os entraves para o desenvolvimento rural em bases sustentáveis. In $17^{\circ}$ Seminário sobre a Economia Mineira, 2016, Diamantina. Anais. Diamantina. Disponível em: https://revistas.ufpr.br/made/article/view/62145 Acesso em 27/12/2020.

PNUD; et al. Atlas: mapeando os objetivos de desenvolvimento sustentável na mineração. 2017. Disponível em: https://www.br.undp.org/content/brazil/pt/home/library/ods/atlas--mapeando-osobjetivos-de-desenvolvimento-sustentavel-na-m.html Acesso em 06 out. 2019. 
RESERVAS VOTORANTIM. Legado das Águas. 2019. Reservas Votorantim. Disponível em: https://legadodasaguas.com.br/o-legado/ Acesso em: 30/01/2019.

SANTIAGO, A. L. F. Licença social para operar relacionamento da empresa com a comunidade local: critérios de influência para a concessão da LSO. Um estudo de caso da mineração brasileira. 2016. 318 f. Tese (Doutorado em Administração de Empresas) - Centro Universitário FEI, São Paulo, 2016. Disponível em: https://repositorio.fei.edu.br/handle/FEI/185 Acesso em: 12 nov. 2020.

SEPE, J; SALVADOR, N. N. B Impactos da mineração e conflitos pelo uso da água com as atividades agrícolas de pequeno porte. In VIII Simpósio Reforma agrária e Questões Rurais, 2018, São Paulo. Anais.

São

Paulo.

Disponível

em:

https://www.uniara.com.br/legado/nupedor/nupedor_2018/Sessao5A.html

VALE, Relatório de Sustentabilidade Vale: 2019., [S. 1.], p. 74-76, 31 dez. 2019. Disponível em: http://www.vale.com/brasil/PT/sustainability/relatorio-de-sustentabilidade-2019/ Acesso em: 27 jan. 2021.

VILHENA, J. M. Modelo de integração das questões sociais no desenvolvimento de megaprojetos no setor de mineração: um caminho para a construção da licença social para operar. 2019. Dissertação (Mestrado) - Engenharia de Civil, Belo Horizonte, 2019 Disponível em: https://repositorio.ufmg.br/handle/1843/30901. Acesso em: 21 mar. 2021.

ERNST \& YOUNG. (2015). Business risks facing mining and metals in 2015-16. EY, 41. Disponível em: https://www.shinnihon.or.jp/shinnihon-library/publications/research/2015/pdf/201509-14-en.pdf. Acesso em $15 \mathrm{dez} 2020$.

ERNST \& YOUNG. (2019). Top 10 business risks facing mining and metals in 2019-20. EY, 2-3. Disponível em: https://www.ey.com/en_gl/mining-metals/10-business-risks-facing-mining-and$\underline{\text { metals }}$ Acesso em $15 \mathrm{dez} 2020$.

WANDERLEY, L. J. M. Deslocamento compulsório e estratégias empresariais em áreas de mineração: um olhar sobre a exploração de bauxita na Amazônia. Revista IDeAS - Interfaces em Desenvolvimento, Agricultura e Sociedade, Rio de Janeiro - RJ, v. 3, n. especial, p. 475-509, 2009

Abstract: The purpose of this article is to debate how the Society is important for mining and how mining companies have acted to revert the harmful aspects and create value. Therefore, showing that mining sector has stopped to act causing high degradation of environment and seeks, increasingly, sustainable development in environmental, social and economic terms. Looking for improvement it is essential to understand how the mining bidding process works, the problems caused over time and the way improvements are proposed. In this context, the article calls into question the various conflicts, rewarding projects and their results, highlighting society's position as a stakeholder. From this, it is possible to understand the performance of mining companies and their importance for communities to develop and achieve the UN Sustainable Development Goals.

Keywords: Sustanaible Mining. Social License. ODS. 